\title{
BMJ Open Six-year follow-up of the SPHERE RCT: secondary prevention of heart disease in general practice
}

\author{
A W Murphy, ${ }^{1}$ M E Cupples, ${ }^{2}$ E Murphy, ${ }^{1} \mathrm{~J}$ Newell, ${ }^{3} \mathrm{C}$ J Scarrott, ${ }^{4}$ A Vellinga, ${ }^{1}$ \\ P Gillespie, ${ }^{5}$ M Byrne, ${ }^{6} \mathrm{C}$ Kearney, ${ }^{1} \mathrm{~S} \mathrm{M}$ Smith ${ }^{7}$
}

To cite: Murphy AW,

Cupples ME, Murphy E, et al.

Six-year follow-up of the

SPHERE RCT: secondary

prevention of heart disease in

general practice. BMJ Open

2015;5:e007807.

doi:10.1136/bmjopen-2015007807

- Prepublication history for this paper is available online. To view these files please visit the journal online (http://dx.doi.org/10.1136/ bmjopen-2015-007807).

Received 6 February 2015 Accepted 13 April 2015

CrossMark

For numbered affiliations see end of article.

Correspondence to Professor AW Murphy; andrew.murphy@nuigalway.ie

\section{ABSTRACT}

Objective: To determine the long-term effectiveness of a complex intervention in primary care aimed at improving outcomes for patients with coronary heart disease.

Design: A 6-year follow-up of a cluster randomised controlled trial, which found after 18 months that both total and cardiovascular hospital admissions were significantly reduced in intervention practices (8\% absolute reduction).

Setting: 48 general practices in the Republic of Ireland and Northern Ireland.

Participants: 903 patients with established coronary heart disease at baseline in the original trial.

Intervention: The original intervention consisted of tailored practice and patient plans; training sessions for practitioners in medication prescribing and behavioural change; and regular patient recall system. Control practices provided usual care. Following the intervention period, all supports from the research team to intervention practices ceased.

Outcome measures: Primary outcome: hospital admissions, all cause and cardiovascular; secondary outcomes: mortality; blood pressure and cholesterol control.

Results: At 6-year follow-up, data were collected from practice records of 696 patients $(77 \%)$. For those who had died, we censored their data at the point of death and cause of death was established. There were no significant differences between the intervention and control practices in either total (OR $0.83(95 \% \mathrm{Cl} 0.54$ to 1.28)) or cardiovascular hospital admissions (OR 0.91 ( $95 \% \mathrm{Cl} 0.49$ to 1.65$)$ ). We confirmed mortality status of 886 of the original 903 patients $(98 \%)$. There were no significant differences in mortality $(15 \%$ in intervention and $16 \%$ in control) or in the proportions of patients above target control for systolic blood pressure or total cholesterol.

Conclusions: Initial significant differences in the numbers of total and cardiovascular hospital admissions were not maintained at 6 years and no differences were found in mortality or blood pressure and cholesterol control. Policymakers need to continue to assess the effectiveness of previously efficacious programmes.

Trial registration number: Current Controlled Trials ISRCTN24081411.

\section{Strengths and limitations of this study}

- Strengths include the original study design, the sample size and the length of follow-up.

- The significant differences in the numbers of total and cardiovascular hospital admissions observed at the end of the initial intervention period were not maintained at 6 years, pointing to a need for research into the potential benefit of delivering previously efficacious interventions intermittently over time, based on regular assessments of incentive effects.

- The main limitation to this study is that common to all trial follow-up studies: crossover between the intervention and control practices, in terms of the management of secondary prevention, could have occurred on study cessation at 18 months.

\section{INTRODUCTION}

Secondary prevention of coronary heart disease (CHD), which aims to prevent acute coronary events and optimise well-being among those with established CHD, is widely advocated and promoted. Secondary prevention is multifaceted, including pharmaceutical interventions to manage blood pressure and cholesterol and interventions to change behaviour and lifestyle. Health systems in developed countries now invest considerable, and recurrent, resources in cardiac secondary prevention.

General practice plays an important role in secondary prevention. Two systematic reviews of cardiac secondary prevention programmes have demonstrated improved process (eg, cholesterol management) and outcome (eg, mortality). ${ }^{12}$ However, both noted that there was some evidence of a 'ceiling effect' whereby interventions have a diminishing beneficial effect once certain levels of risk marker management are reached. Clark $e t a l^{2}$ and McAlister et $a \hat{l}$ also recommended a rigorous evaluation of long-term clinical and economic outcomes. 
An important contributor to the first review was our own SPHERE cluster randomised controlled trial. We found that a complex 18-month intervention with tailored plans for general practices and patients, which aimed to improve outcomes for patients with CHD, resulted in significantly reduced hospital admissions but showed no other benefits, possibly because of a ceiling effect. The current follow-up study is intended to contribute to an ongoing systematic review of long-term follow-up studies of primary care organisational interventions for the secondary prevention of ischaemic heart disease. $^{4}$

We now report follow-up of the SPHERE participants after 6 years to first determine if the positive impact of our 18-month intervention on hospital admissions for patients with established CHD persisted and, second, to determine the long-term impact on mortality and on blood pressure and cholesterol control.

\section{METHODS}

We reported full details of recruitment, randomisation and the intervention previously. ${ }^{5}$ Briefly, in 2004-2005, we recruited 48 randomly selected general practices in the Republic of Ireland and Northern Ireland. In each practice, patients with established CHD, determined by documented myocardial infarction, coronary artery bypass grafting, angioplasty or angina (confirmed by exercise stress test, isotope test or coronary angiogram), were identified. Patients with a major mental or physical illness that would impair their ability to take part in the intervention (as determined by the general practitioner (GP)) were excluded. Randomly selected eligible patients were invited to participate and were asked to return study postal questionnaires. Following baseline data collection, practices were randomised to intervention and control by an individual independent of the research team.

\section{INTERVENTION}

The intervention consisted of: (1) tailored practice plans (action plans for practices were developed and reviewed; practices received a regular SPHERE study newsletter); (2) two training sessions for practitioners in medication prescribing and behavioural change; (3) tailored patient care plans (patient information booklet provided; patients identified one aspect of secondary prevention to focus on; goals and action plans developed; progress reviewed) and (4) regular patient recall system established where patients were invited to consult with the GP or practice nurse every 4 months. The intervention was developed on the basis of a review of the literature and psychological theory, mainly social cognitive theory, and modelled following qualitative research and piloting. ${ }^{6}$ Control practices continued with usual care $^{5}$ and, following the intervention period, all supports from the research team to intervention practices ceased.

\section{FOLLOW-UP}

In 2012, 6 years after randomisation, we traced the original participants through their general practices and obtained their consent to collect data from their practice records. For those who had moved practice within Ireland, we made every attempt to follow them to their new practices. Patients who moved abroad were lost to follow-up.

From the practice records, research nurses collected data on risk factors, medication prescribing, hospital admissions and length of stay and on coronary events and procedures. Owing to resource limitations, only four of the five research nurses were blinded to the group allocation. Blood pressure and cholesterol data recorded in the practice records within 12 months of the end of the follow-up period were accepted.

For those who had died, we censored their data at the point of death and obtained confirmation of the cause of death from the General Registry Office (Republic of Ireland) or from the practice records (Northern Ireland). This study was approved by the Irish College of General Practitioners and the Office of the Research Ethics Committees Northern Ireland.

\section{OUTCOME MEASURES}

The primary outcome measure was hospital admissions from practice records. These were calculated for both all cause and cardiovascular related. An admission was attributed to a cardiovascular cause only if a cardiovascular diagnosis or procedure was stated as a primary reason for an admission. Secondary outcomes included mortality and blood pressure and cholesterol control. Mortality was also calculated for both all cause and cardiovascular related. A death was attributed to a cardiac cause only if the primary cause of death was cardiac. Lack of control was defined as follows: systolic blood pressure $>140 \mathrm{~mm} \mathrm{Hg}$, diastolic blood pressure $>90 \mathrm{~mm} \mathrm{Hg}$ and cholesterol level $>5.0 \mathrm{mmol} / \mathrm{L}$.

\section{SAMPLE SIZE}

Detailed sample size calculations for the original trial are described elsewhere. ${ }^{7}$ We achieved the original intended sample size.

\section{STATISTICAL ANALYSIS}

The design employed was that of a longitudinal cluster randomised trial with inpatient hospital admissions, a count variable, as the primary response.

Initially, a Poisson regression model was used. Since many participants had no admissions in a given time period, two approaches were then used to adjust for overdispersion: a zero inflated Poisson regression model and a Hurdle model. All models incorporated random effects for clustering in the data due to randomisation by general practice and for the correlation due to the repeated measurements for each individual across time. 
The Hurdle model $^{8}$ splits the problem into two parts: initially, the presence and absence of admissions are modelled using a logistic component and then the mean count, for those with at least one admission, is modelled using a (truncated) Poisson regression. Therefore, whether a hospital admission occurs is considered first, followed by then describing the mean number of admissions observed. We only report the results of the logistic component of the Hurdle model in this paper; the zero inflated Poisson regression gave similar conclusions (data available from authors). There were no baseline data on cardiovascular admissions, so the total hospital admissions were used as a proxy based on the assumption that the proportion of cardiovascular and non-cardiovascular admissions was the same in the intervention and control groups before baseline.

Linear and non-linear mixed models, which accounted for missing values, were used to model the variability in continuous (eg, blood pressure) and categorical (eg, proportions outside secondary prevention guidelines) responses, using prespecified variables (GP cluster, baseline response, practice size, practice location, age, gender, years since diagnosis and conditions at baseline: angina, MI, CABG, PTCA and diabetes). The log rank test was used to compare survival distributions. All analyses were carried out using $\mathrm{R}$ (2.15), using the nlme, lme4, glmmADMB, ggplot2 and survival libraries.

\section{RESULTS}

Table 1 shows that characteristics of the 48 practices and the 903 participants enrolled in the original SPHERE study were well balanced at baseline, apart from occupational status and educational level.

Figure 1 shows the flow of practices and patients through the study. For everyone alive at 6 years, follow-up was exactly 6 years from baseline. No practices were lost to follow-up. Data were collected from the practice records of 696 patients, $339(76 \%)$ in the intervention group and $357(78 \%)$ in the control group. It was not possible to collect follow-up practice record data for 207 patients: in total, 68 did not respond to the invitation to participate, 31 declined to participate, 78 were not contactable and 30 died during the original intervention period-all equally divided across arms. Of the original 903 patients, mortality status was confirmed for $886(435+451(98 \%))$.

\section{HOSPITAL ADMISSIONS}

There were a large number of patients with no admissions in any given time period $(70-84 \%)$. Table 2 shows

Table 1 Characteristics of the practices and patients at baseline

\begin{tabular}{|c|c|c|}
\hline Characteristic & Intervention number (\%) & Control number (\%) \\
\hline \multicolumn{3}{|l|}{ Practice factors } \\
\hline Number of practices & 24 & 24 \\
\hline \multicolumn{3}{|l|}{ Practice size } \\
\hline$<2$ whole time equivalents & $9(47)$ & $10(53)$ \\
\hline$\geq 2$ whole time equivalents & $15(52)$ & $14(48)$ \\
\hline \multicolumn{3}{|l|}{ Region } \\
\hline Northern Ireland & $8(33)$ & $8(33)$ \\
\hline Republic of Ireland & $16(67)$ & $16(67)$ \\
\hline \multicolumn{3}{|l|}{ Patient factors } \\
\hline Number of patients & 444 & 459 \\
\hline Men & $312(70)$ & $321(70)$ \\
\hline Mean (SD) age (years) & $68.5(9.3)$ & $66.5(9.9)$ \\
\hline Mean (SD) years since diagnosis & $8.3(6.6)$ & $8.2(6.5)$ \\
\hline Myocardial infarction & $220(50)$ & $233(51)$ \\
\hline Angina & $390(88)$ & $414(90)$ \\
\hline Diabetes & $78(17.6)$ & $82(17.9)$ \\
\hline Coronary artery bypass grafting & $114(25.7)$ & $124(27.1)$ \\
\hline PTCA & $126(28.4)$ & $149(32.6)$ \\
\hline Eligible for General Medical Scheme* & 234 (82.4) & $218(73.4)$ \\
\hline Married & $288(67)$ & $315(70)$ \\
\hline Manual occupation $\dagger$ & $134(42)$ & $172(51)$ \\
\hline Completed secondary education† & $179(42)$ & $145(33)$ \\
\hline \multicolumn{3}{|l|}{ Physiological variables } \\
\hline Mean (SD) systolic blood pressure $(\mathrm{mm} \mathrm{Hg})$ & $136.2(22.2)$ & $136.8(21.2)$ \\
\hline Mean (SD) diastolic blood pressure $(\mathrm{mm} \mathrm{Hg})$ & $78.4(12.0)$ & 79.5 (11.3) \\
\hline Mean (SD) total cholesterol $(\mathrm{mmol} / \mathrm{L})$ & $4.40(0.90)$ & $4.34(0.92)$ \\
\hline
\end{tabular}




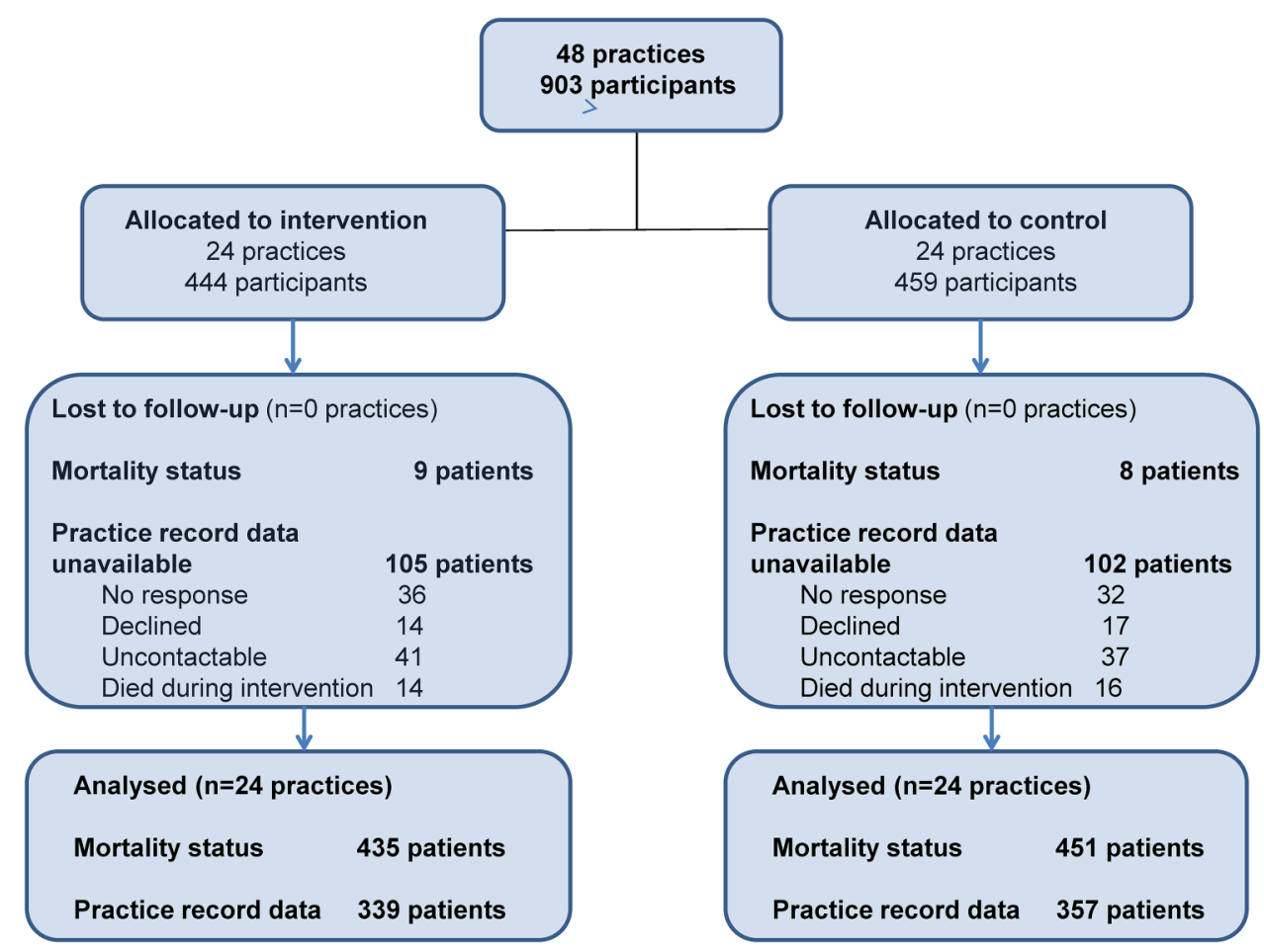

Figure 1 Flow of practices and patients through the 6-year study period. No response: participants to whom an invitation to take part in the follow-up study was sent but who did not respond. Uncontactable: participants who were not invited, for a variety of reasons, to take part in the follow-up, for example, the GP advised not to contact due to severe illness, onset of dementia, family bereavement or where a participant moved general practice and contact details were no longer available.

the mean number of all-cause admissions and table 3 shows the mean number of cardiovascular hospital admissions for all patients across all time points.

Admission counts were converted to annualised values when applying the linear mixed models, to make the responses equivalent measures. The results from the logistic component of the Hurdle model (table 4) show that, for both all-cause and cardiovascular admissions, the significant differences found in the original SPHERE study at 18 months persist in the 12-month equivalent analysed here, but are not apparent at 24, 36, 48,60 or 72 months.

Table 2 Mean number of all-cause hospital admissions at each time point

\begin{tabular}{llllllll}
\hline & \multicolumn{3}{l}{ Intervention } & & \multicolumn{3}{l}{ Control } \\
\cline { 2 - 3 } Time point & $\mathbf{N}$ & Mean & SD & & $\mathbf{N}$ & Mean & SD \\
\hline Baseline & 440 & 0.30 & 0.59 & 452 & 0.44 & 0.77 \\
18 months & 425 & 0.38 & 0.74 & 444 & 0.55 & 0.98 \\
2 years* & 335 & 0.17 & 0.49 & 357 & 0.22 & 0.54 \\
3 years & 329 & 0.33 & 0.79 & 352 & 0.39 & 0.84 \\
4 years & 322 & 0.36 & 0.79 & 341 & 0.40 & 0.79 \\
5 years & 317 & 0.39 & 0.77 & 335 & 0.35 & 0.72 \\
6 years & 312 & 0.30 & 0.73 & 330 & 0.37 & 0.82 \\
\hline
\end{tabular}

*The first time period is 18 months, followed by a 6 -month time period, with all others on a yearly basis.

\section{MORTALITY}

There was no evidence that total or cardiac mortality at 6-year follow-up differed between the intervention and control groups, with $15 \%$ deceased in the intervention group and $16 \%$ in the control group $\left(\chi^{2}\right.$ test, $\left.\mathrm{p}=0.83\right)$ (table 5). There was no difference in survival functions between the two groups (Log Rank test, $\mathrm{p}=0.68$ ).

\section{BLOOD PRESSURE AND TOTAL CHOLESTEROL CONTROL}

Table 6 shows the percentage of participants outside appropriate secondary prevention risk marker guidelines

Table 3 Mean number of cardiovascular hospital admissions at each time point

\begin{tabular}{lllllllll}
\hline & \multicolumn{3}{l}{ Intervention } & & \multicolumn{3}{l}{ Control } \\
\cline { 2 - 3 } Time point & $\mathbf{N}$ & Mean & SD & & & Mean & SD \\
\hline 18 months $^{*}$ & 425 & 0.14 & 0.51 & & 444 & 0.23 & 0.70 \\
2 years* & 335 & 0.06 & 0.27 & & 357 & 0.07 & 0.35 \\
3 years & 329 & 0.10 & 0.36 & & 352 & 0.12 & 0.41 \\
4 years & 323 & 0.10 & 0.35 & & 341 & 0.13 & 0.38 \\
5 years & 316 & 0.15 & 0.44 & & 335 & 0.11 & 0.37 \\
6 years & 313 & 0.09 & 0.35 & & 330 & 0.11 & 0.39 \\
\hline
\end{tabular}

*The first time period is 18 months, followed by a 6-month time period, with all others on a yearly basis. There were no baseline data on cardiovascular admissions, so the total hospital admissions were used as a proxy in all models. 
Table 4 OR of an admission and a cardiovascular admission in the intervention and control groups during follow-up, using the logistic component of a Hurdle model

\begin{tabular}{lllllll}
\hline $\begin{array}{l}\text { Follow-up } \\
\text { (months) }\end{array}$ & $\begin{array}{l}\text { OR for hospital } \\
\text { admissions (intervention } \\
\text { vs control) }\end{array}$ & $\mathbf{9 5 \%} \mathbf{C l}$ & $\mathbf{p ~ V a l u e}$ & $\begin{array}{l}\text { OR for CV hospital } \\
\text { admissions (intervention } \\
\text { vs control) }\end{array}$ & $\mathbf{9 5 \%} \mathbf{~ C l ~}$ & p Value \\
\hline $12 \dagger$ & 0.65 & 0.46 to 0.92 & 0.01 & 0.62 & 0.39 to 0.98 & 0.04 \\
$24 \dagger$ & 0.64 & 0.39 to 1.04 & 0.07 & 0.89 & 0.43 to 1.83 & 0.76 \\
36 & 0.74 & 0.49 to 1.12 & 0.16 & 0.89 & 0.51 to 1.56 & 0.69 \\
48 & 0.87 & 0.58 to 1.31 & 0.51 & 0.74 & 0.43 to 1.29 & 0.29 \\
60 & 1.19 & 0.79 to 1.80 & 0.40 & 1.39 & 0.81 to 2.40 & 0.23 \\
72 & 0.83 & 0.54 to 1.28 & 0.40 & 0.91 & 0.49 to 1.65 & 0.75 \\
\hline
\end{tabular}

${ }^{*}$ OR adjusted for GP cluster, baseline inpatient admissions, practice size, practice location, age, gender, years since diagnosis and conditions at baseline: angina, MI, CABG, PTCA and diabetes.

tData were originally collected at the end of the 18-month intervention and the first follow-up period was 6 months, so these are based on annualised equivalents of the admission counts.

GP, general practitioner.

at baseline and at 18 months and 6 years. The proportion of patients outside of the recommended guidelines decreased from baseline to 6-year follow-up, but the differences between groups were not significant.

\section{DISCUSSION}

We found that after 6 years of follow-up of patients with established heart disease randomised to a complex intervention with tailored plans for general practices and patients or usual care, initial significant differences at 18 months in the numbers of all-cause and cardiovascular hospital admissions were not maintained. At the 6-year follow-up, there were also no differences in mortality or blood pressure and cholesterol control.

Three other equivalent studies have reported similar follow-up periods: Cupples in Belfast, ${ }^{9}$ Murchie in north east Scotland $^{10}$ and Munoz in Catalonia. ${ }^{11}$ None reported similar admission data. Murchie reported significantly lower cumulative death rates, in favour of intervention practices, of $14.5 \%$ and $18.9 \% \quad(p=0.038)$. Cupples reported similar proportions; Munoz found no significant differences in mortality. We are currently conducting a systematic review of all follow-up studies of cardiac secondary prevention programmes in general practice. ${ }^{4}$ The Belfast and Scottish studies were initially conducted in the early and mid-1990s, respectively, when control of cardiovascular risk markers for patients with established heart disease was poorer than it is now. For example, the mean baseline cholesterol was $6.2 \mathrm{mmol} / \mathrm{L}$ in Belfast, while the mean Scottish baseline cholesterol was $6.5 \mathrm{mmol} / \mathrm{L}$. These are much higher than what we found at baseline in 2005 (table 1), which in turn are similar to those found by Munoz et $a l^{12}$ in 2001.

\section{IMIPLICATIONS FOR PRACTICE AND RESEARCH}

As suggested by the two systematic reviews, ${ }^{12}$ it may be that with improved secondary cardiac risk profiles for both individuals and the general population, a ceiling has now been reached. Gains previously possible in risk marker management may no longer be attainable. Table 6 highlights the importance of control groups as the cholesterol and blood pressure control improved generally over time. Policymakers need to continue to assess the effectiveness of previously efficacious programmes. From an economic perspective, the additional cost of delivering the intervention for 18 months was offset by the savings generated from reduced hospital admissions, leading to an overall reduction in healthcare costs relative to control at 18 months with no impact on patient health status. ${ }^{13}$ Ongoing analysis for our upcoming paper on the cost-effectiveness of the SPHERE intervention at 6 years will provide further insight on this question.

The ongoing effects of incentivising or supporting interventions need to be balanced with a consideration of the opportunity costs for such incentives. Behavioural research has confirmed that the impact of a behavioural intervention diminishes once the intervention ceases. ${ }^{14}{ }^{15}$ Research is needed into the potential benefit of intermittent incentives or support for interventions using some sort of 'turn on, turn off' approach based on regular assessments of programme or incentive effects.

\section{LIMITATIONS}

The main limitation to this study is that common to all trial follow-up studies: crossover between the intervention and control practices, in terms of the management of secondary prevention, could have occurred on study

Table 5 Total and cardiac mortality at 6 years

\begin{tabular}{lllll}
\hline & Alive, $\mathbf{n}(\%)$ & Deceased, $\mathbf{n}(\%)$ & Cardiac cause of death, $\mathbf{n}(\%)^{*}$ & Not established, $\mathbf{n}(\%)$ \\
\hline Intervention & $370(83)$ & $65(15)$ & $29(45)$ & $9(2)$ \\
Control & $378(82)$ & $73(16)$ & $32(44)$ & $8(2)$ \\
\hline${ }^{*}$ Of those who died in that study group. & & &
\end{tabular}




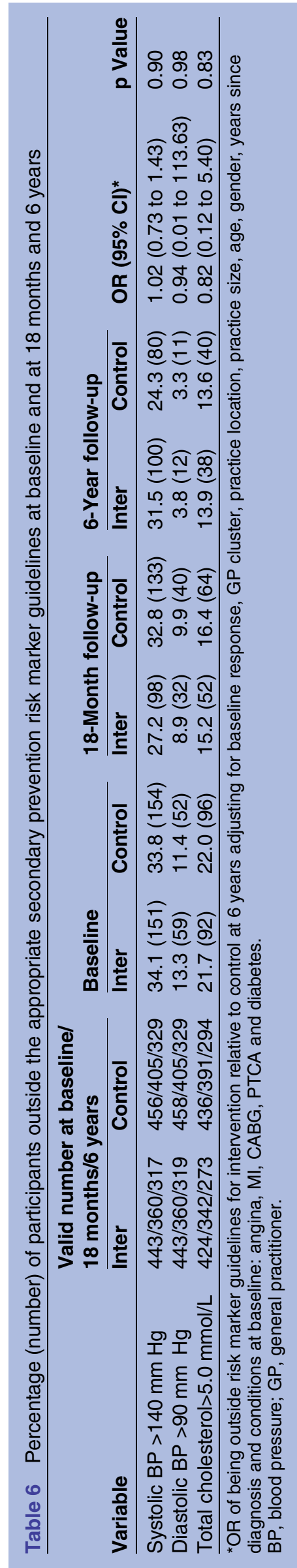

cessation at 18 months. We simply do not know whether intervention practices ceased to provide the intervention, or control practices introduced similar approaches, or a mixture of both. This potentially could result in a significant difference being missed at the follow-up point and a type II error. The trends over time in tables 4 and 6 do not suggest this. Classification of admissions into cardiovascular or not was dependent on routine admission records.

We suggest that it would be helpful if there were general guidelines on how best to report long-term follow-up studies of trials.

\section{Author affiliations}

${ }^{1}$ Discipline of General Practice, National University of Ireland, Galway, Ireland ${ }^{2}$ UKCRC Centre of Excellence for Public Health (Northern Ireland), Queen's University Belfast, Belfast, Northern Ireland

${ }^{3}$ Health Research Board Clinical Research Facility, National University of Ireland, Galway, Ireland

${ }^{4}$ School of Mathematic and Statistics, University of Canterbury, Christchurch, New Zealand

${ }^{5}$ School of Business and Economics, National University of Ireland, Galway, Ireland

${ }^{6}$ School of Psychology, National University of Ireland, Galway, Ireland ${ }^{7}$ Department of General Practice, Royal College of Surgeons in Ireland, Dublin, Ireland

Acknowledgements The authors thank the research nurses who collected the study data and the Northern Ireland Clinical Research Network (Primary Care) for support, led by Claire Leathem. They thank the patients and practitioners in each of the participating practices: Medical Centre, Tallaght; Medical Centre, Kilcullen; Guinness Medical Centre, Dublin 8; Beechlawn Medical Centre, Monkstown; Medical Centre, Carrig, Kill, Co Kildare; Unit 3 Neilstown Shopping Centre, Clondalkin; Derrinturn Health Centre, Carbury, Co Kildare; Medical Centre, Blessington, Co Wicklow; 276 River Forest, Leixlip; Ballymun Family Practice, Ballymun Health Centre, Dublin 11; Medical Centre, Main. Street, Celbridge, Co Kildare; Kildare Medical Centre, Bride Street, Kildare, Co Kildare; Bray Family Practice, Meath Road, Bray, Co Wicklow; 2a

BrookdaleWalk, Swords, Co Dublin; 138 Collins Avenue, Whitehall, Dublin 9; 31 Hazelwood Court, Artane, Dublin 5; Springfield Medical Centre, Alderwood Avenue, Tallaght; Primary Care Centre, Mohill, Co Leitrim; Medical Centre, Carrigart, Co Donegal; Millbrae Surgery, Carndonagh, Co Donegal; Claddagh Medical Centre, The Crescent, Galway; Medical Centre, Westport Road, Clifden, Co Galway; 4 Howley Terrace, Ballina, Co Mayo; Grove Medical Centre, Westport, Co Mayo; Eastland House, Dublin Road, Tuam, Co Galway; Health Centre, Athenry, Co Galway; Medical Centre, Carrowmore, Knock, Co Mayo; Health Centre, Moville, Co Donegal; Caheroyn Crescent, Athenry, Co Galway; Medical Centre, Dublin Road, Tuam, Co Galway; 216 Upper Salthill, Galway, Co Galway; Medical Centre, Kevin Barry Street, Ballina, Co Mayo; Medical Centre, Bangor Erris, Co Mayo; Health Centre, Turloughmore, Co Galway; Bangor Health. Centre, Newtownards Road, Bangor; Ballywalter Health Centre, Fowler Way, Ballywalter; Old Mill Surgery, Church Street, Newtownards; Duncairn Surgery, Duncairn Gardens, Belfast; Kerrsland Surgery,Upper Newtownards Road, Belfast; Glenavy Family Practice, Main Street, Glenavy, Crumlin; Parkside Surgery, Grove Wellbeing Centre, Belfast; Level 2, Lisburn Health Centre; Comber Health Centre, Newtownards Road, Comber; Thames Street Surgery, 2 Thames Street, Belfast; Cuan Clinic, The Health Centre, High Street, Portaferry; Cornerstone Medical Centre (Cityview and Collins and Currie Practices) 69 Shankill Road, Belfast, Loughview Medical Centre, Main Street, Kircubbin; Level 3, Lisburn Health Centre, Lisburn; Falls Family Doctors, Falls Road Medical Centre, Belfast; Stream Street Surgery, Downpatrick, Co Down; Woodbrook Medical Centre, Stewartstown Road, Dunmurry, Belfast.

Contributors AWM, MEC, SMS, JN, MB and PG conceived the study and together with $\mathrm{AV}$ and $\mathrm{EM}$ participated in the design of the follow-up study. All authors, including CK and CJS, participated in the acquisition and analysis of 
data and in the critical revision of the manuscript; they have seen and approved the final version. AWM is the guarantor.

Funding This study was funded by the Health Research Board, Ireland.

Competing interests None declared.

Patient consent Obtained.

Ethics approval This study was approved by the Irish College of General Practitioners and the Office of the Research Ethics Committees Northern Ireland.

Provenance and peer review Not commissioned; externally peer reviewed.

Data sharing statement Data will be made available through The Irish Social Science Data Archive (ISSDA) - Ireland's leading centre for quantitative data acquisition, preservation and dissemination. The original SPHERE data set is available there also.

Open Access This is an Open Access article distributed in accordance with the Creative Commons Attribution Non Commercial (CC BY-NC 4.0) license, which permits others to distribute, remix, adapt, build upon this work noncommercially, and license their derivative works on different terms, provided the original work is properly cited and the use is non-commercial. See: http:// creativecommons.org/licenses/by-nc/4.0/

\section{REFERENCES}

1. Buckley BS, Byrne MC, Smith SM. Service organisation for the secondary prevention of ischaemic heart disease in primary care. Cochrane Database Syst Rev 2010;(3):CD006772.

2. Clark AM, Hartling L, Vandermeer B, et al. Meta-analysis: secondary prevention programs for patients with coronary artery disease. Ann Intern Med 2005;143:659-72.

3. McAlister FA, Lawson FM, Teo KK, et al. Randomised trials of secondary prevention programmes in coronary heart disease: systematic review. BMJ 2001;323:957-62.

4. Murphy E, Vellinga A, Murphy AW, et al. Long-term outcomes of organizational interventions for the secondary prevention of ischaemic heart disease in primary care and community settings. 1 September 2013. 2012. http://www.crd.york.ac.uk/PROSPERO/ display_record.asp?ID=CRD42012003136

5. Murphy AW, Cupples ME, Smith SM, et al. Effect of tailored practice and patient care plans on secondary prevention of heart disease in general practice: cluster randomised controlled trial. BMJ 2009;339: b4220.

6. Byrne M, Cupples ME, Smith SM, et al. Development of a complex intervention for secondary prevention of coronary heart disease in primary care using the UK Medical Research Council framework. Am J Manag Care 2006;12:261-6.

7. Murphy AW, Cupples ME, Smith SM, et al. The SPHERE Study. Secondary prevention of heart disease in general practice: protoco of a randomised controlled trial of tailored practice and patient care plans with parallel qualitative, economic and policy analyses. [ISRCTN24081411]. Curr Control Trials Cardiovasc Med 2005;6:11.

8. Hur K, Hedeker D, Henderson W, et al. Modeling clustered count data with excess zeros in health care outcomes research. Health Serv Outcomes Res Methodol 2002;3:5-20.

9. Cupples ME, McKnight A. Five year follow up of patients at high cardiovascular risk who took part in randomised controlled trial of health promotion. BMJ 1999;319:687-8.

10. Murchie P, Campbell NC, Ritchie LD, et al. Secondary prevention clinics for coronary heart disease: four year follow up of a randomised controlled trial in primary care. BMJ 2003;326:84.

11. Muñoz MA, Subirana I, Ramos R, et al. Efficacy of an intensive prevention programme of coronary heart disease: 5 year follow-up outcomes. Med Clin (Barc) 2008;130:521-5.

12. Munoz MA, Vila J, Cabañero M, et al. Efficacy of an intensive prevention program in coronary patients in primary care, a randomised clinical trial. Int J Cardiol 2007;118:312-20.

13. Gillespie P, O'Shea E, Murphy AW, et al. The cost-effectiveness of the SPHERE intervention for the secondary prevention of coronary heart disease. Int J Technol Assess Health Care 2010;26: 263-71.

14. Norris SL, Lau J, Smith SJ, et al. Self-management education for adults with type 2 diabetes a meta-analysis of the effect on glycemic control. Diabetes Care 2002;25:1159-71.

15. Dansinger ML, Tatsioni A, Wong JB, et al. Meta-analysis: the effect of dietary counseling for weight loss. Ann Intern Med 2007; 147:41-50. 